\title{
Metamerism index of led light on halftone colour images
}

\author{
Igor Zjakic' ${ }^{1}$ Ivana Ljevak², Albulena Bilalli³ \\ ${ }^{1}$ Faculty of Graphic Arts, University of Zagreb, Getaldiceva 2, 10000 Zagreb, Croatia \\ ${ }^{2}$ Meteor Grupa-Labud d.0.0, Radnicka cesta 173, 10000 Zagreb, Croatia \\ ${ }^{3}$ Technical high school, 28 Nentori, Prishtina, Kalabria 12, Qershori
}

\begin{abstract}
Skin face detection in photo imaging is an important component of systems for detecting similarities in visual perception, tracing faces through illumination and metamerism. This paper presents an evaluation of the skin perception under standardized conditions of varied light sources: cool-white fluorescent "store light", 6500K fluorescent "daylight", and incandescent "home light", Led light $6500 \mathrm{~K}, 2700 \mathrm{~K}, 4000 \mathrm{~K}$ CCT (Correlated colour temperature). In cases where the discrepancy is large, the resulting index of metamerism can be misleading. A small index of metamerism and a large change of color under illuminant metamerism has a different interpretation than what is perceived. This has been demonstrated through small colour variations in print through CMYK colors. The implication is that the particular indices of metameric should only account for a limited range under different light conditions.

The method used in this paper is based on visual perception, which aims to work with a wide variety of individuals, under varying lighting conditions under the influence of standard daylight, but in this case we also used the Led light $6500 \mathrm{~K}$ correlated colour temperature, and variations of skin color tones, comparing the illuminant metamerism of visual perception based on different reflectance power distributions (SPDs).
\end{abstract}

Keywords: Light sources, visual perception, illuminant metamerism, human skin color detection

\section{Introduction}

The purpose of this study was to evaluate the effects of illuminant metamerism that affect the visual perception of colors. The resemblance of illuminant metamerism is usually assessed by measuring the color variation and proximity under the test conditions.

In this paper we used binocular subjective matching method and compared it with spectrophotometric measurements through various spectral power distributions.

Spectral imaging has become a topic of growing interest in color-reproduction, remote-sensing, medical imaging, and other systems, so these research efforts are likely to be distributed into other application fields such as computer vision and pattern acquaintance [1]. Different technologies lead to different spectral radiances and as a consequence, colored objects can appear different. In this paper we used CMYK color space which although not often used in image processing, especially in skin detecting similarities through different light temperatures and light sources, turned out to be a good choice. As an example, the skin face detection image was illuminated by different light sources, with matching CCT, luminance, and dissimilar spectral radiance. Hereby the question is, which variations of the chosen sample were identified as the most similar to the original photo color of the skin? 
Different cameras affect the color values as well. Movement of an object can cause blurring of colors. Finally, skin tones vary dramatically within and across individuals [2].

\section{Correlated color temperature (CCT)}

Certain properties of light sources are described by the terms such as color temperature, distribution temperature, and CCY.

The term color temperature refers to highly selective radiators, the term "distribution temperature" as the property of light source has to do with the absolute temperature (in $\mathrm{K})$ of the blackbody radiator for which the spectral radiant power is proportional to that of the source considered at every wavelength in the visible spectrum. At specific absolute temperature, the spectral radiant power distribution of tungsten filament sources approximate those of blackbody radiators. The term color temperature or distribution temperature is irrelevant to these sources. [3]
Initially (in 1931) three standards illuminants were defined, termed illuminants A, B and C, the spectral power distribution of a typical tungsten incandescent lamp was represented by illuminant $A$, sunlight is represented directly by illuminant $B$ with a CCT of approximately $4900 \mathrm{~K}$, where the average of daylight with a CCT of $6800 \mathrm{~K}$ is represented by illuminant $\mathrm{C}$. According to the latest CIE recommendations and standards, the special status of a CIE standard illuminant are given only to two illuminants; illuminants $\mathrm{A}$ and D65. [4]

However the CIE recommendations on colorimetry (CIE, 2004) also include tabulated values for three other daylight illuminants (D50, D55, and D75) and equations are given for calculation of the spectral power distributions of other daylight illuminants, based on their nominal CCTs.

Lights can be designed to have the same CCT and luminance such as soft-white light made using incandescent and solid-state technologies.
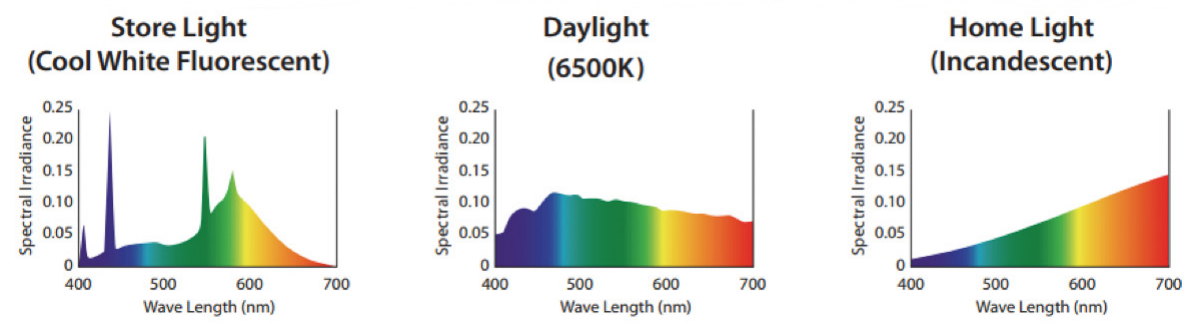

Figure 1. Spectral irradiance of standardized light sources
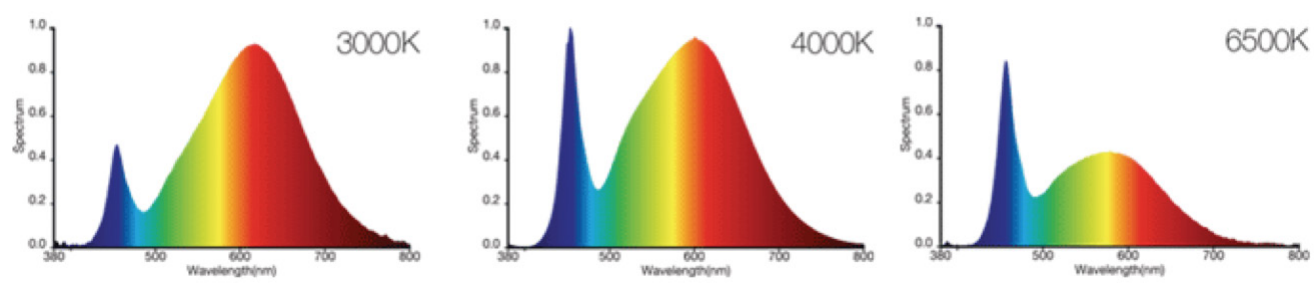

Figure 2. Spectral irradiance of Led lights 
The ideal black body emits the color temperature of the electromagnetic radiation and it is defined as its surface temperature in $\mathrm{K}$, or alternatively in micro. [5] "CCT has always been an important property of lighting and today's solid-state lights for consumer use are designed for four different CCTs, $2700 \mathrm{~K}$, the nominal value of incandescent lights; 3000 $\mathrm{K}$, the nominal value of tungsten-halogen lights; $4000 \mathrm{~K}$, the nominal value of cool-white fluorescent lights, and $5000 \mathrm{~K}$. The adjectives "soft," "bright," and "cool," have been used for 2700,3000 , and $4000 \mathrm{~K}$. Lights that are $5000 \mathrm{~K}$ and above tend to be labeled as "daylight." [6].

\subsection{Led light}

The radiant energy as a source of solid-state to LED produces material which is prepared as a semiconductor, has high purity, added some other chemical compounds that have the function to control "impurity" are added two kinds.

One provides a semiconductor material, called $\mathrm{n}$-type material that excesses of electrons.

The second provides called a-type material that has a shortage of electrons or "holes".

In a narrow spectral area it is isolated the distribution of the spectral LED radiant power. The semiconductor material and the added impurities are two things that are dependent on the wavelength of its peak emission [3].

LED as one of the artificial light sources is incredibly developed in the twenty-first century, 1960s was the year of LED appearance so science has been developed rapidly. During these decades the light has transformed from a single color to multiple colors, from low to high luminance, etc. Every ten years the luminance has reached its increased to 20 times since the appearance of LED, and what is important to emphasize that the price has decreased to $1 \%$ comparing to the original price. Constant development and improvement of this technology, we have seen and experienced dramatic changes as human society. As a light source LED has wide use in many fields such as market, industry, display, transmission, light, etc. What is important to mention that the white LED has a higher modulation bandwidth, and further importance to emphasize is its good modulation performance and high response sensitivity! So through LEDs the signal can be modulated into visible light. 'White LEDs, combining both light and data transmissions, have further promoted the development of VLC technologies [7].

\section{Metamerism}

Metamerism is the most important part that describes color perception, especially from the color technology angle. "Because of the trichromatic nature of our color vision, spectrally dissimilar stimuli can produce the same visual response" [8]. Different reflection or transmission spectra appear to possess the same color under a specific light source. Metameric colors are colors that have the same numerical three-stimulus values, and the different spectral energies of radiation, i.e. the colors of the different spectral energies of radiation that coincide with the observer.

Hereby the phenomenon called metamerism is formed by the color stimuli that have different SPD but match in color for a given observer [3].

"General spectrum and special colorimetry of metamerism, have been developed to access the quality of compatibility for metameric and parametric specimens" [9].

Therefore, we say that there are four types of metamerism:

- illuminant metamerism

- Observer metamerism

- Field size metamerism

- Geometry metamerism 


\subsection{Definition of illuminant metamerism}

Illuminant metamerism caused by a change in illuminant occurs when a metameric couple illuminate by one lighting color experience is the same. Different spectral energies of radiation create a sense of different colors.

Metameric is considered to be metameric color stimuli, and metamerism itself as the concept. The following equation must be according to two metameric color stimuli with different spectral radiant power distribution that are denoted by $\left\{P_{1 \lambda} d \lambda\right\}$ and $\left\{P_{2 \lambda} d \lambda\right\}$

$$
\begin{aligned}
& \int_{\lambda} P_{1 \lambda} \bar{r}(\lambda) d \lambda=\int_{\lambda} P_{2 \lambda} \bar{r}(\lambda) d \lambda \\
& \int_{\lambda} P_{1 \lambda} \bar{g}(\lambda) d \lambda=\int_{\lambda} P_{2 \lambda} \bar{g}(\lambda) d \lambda \\
& \int_{\lambda} P_{1 \lambda} \bar{b}(\lambda) d \lambda=\int_{\lambda} P_{2 \lambda} \bar{b}(\lambda) d \lambda
\end{aligned}
$$

These equations are necessary conditions that are used to complete color match between the two given stimuli of spectral radiant power distributions $\left\{P_{1 \lambda} d \lambda\right\}$ and $\left\{P_{2 \lambda} d \lambda\right\}$.

The stimuli realized by the color matching properties of the observer is defined by the quantities $\bar{r}(\lambda), \bar{g}(\lambda), \bar{b}(\lambda)$.[3].

By illuminating the sample with another source lights, metameric occurs.

Technique of the standard colorimetric that has to do with the composing an identical color coordinate and metameric light spectra meets the challenges in view of the color discrepancy remarked by the observers.

The most important type of metamerism is illuminant metamerism, and illuminant metamerism takes place when two samples appear to match well under one illuminant, but under a second illuminant a large mismatch is exhibited.
For example, the human visual system integrates spectral data with three types of cone receptors to produce a third-channel color image. It is metameric relation because the same color response in the three integrated channels could be produced by an infinite variety of potential spectral power distributions in the scene.[10]

Object-color stimuli of different spectral radiant power distributions

$\left\{\beta^{(1)}(\lambda) S(\lambda) d \lambda\right\}$ and

$\left\{\beta^{(2)}(\lambda) S(\lambda) d \lambda\right\}$ are metameric stimuli with respect to a given observer if they yield identical tristimulus values. However, it is clear that the color match cannot be expected to remain a color match if the illuminant, defined by $\{S(\lambda) d \lambda\} \cdot[3,11]$

\section{Experimental part}

\subsection{Methodology and results}

The main part of this research has been differences in the identification of printed human face skin, comparing visual perception based on different reflectance power distributions (SPDs) through illuminant metamerism. The original photo has been tested by observers with different light sources: Store Light, Day Light, Home Light, Led Light 6500K, Led Light 2700K, Led Light $4000 \mathrm{~K}$ CCT. For this research, a portrait photo of a female is selected together with a grey balance field with rastertone values $(50 \% \mathrm{C}$, $40 \% \mathrm{M}, 40 \% \mathrm{Y}$ ). Before testing all 40 observers successfully past the Ishihara test to check color deficiency. All observers attending in the research were 18 - 55 age old mixed gender (50\%-50\%). Testing was done in the laboratory at the Faculty of Graphic Arts.

The original photo for comparison was printed on glossy offset paper and samples were made on matt offset paper on $90 \mathrm{gm}^{-2}$ 
with electrophotography technique. paper whiteness value was 98 according to ISO 11476:2016.

\subsection{Visual perception testing}

Testing samples were made with small variations in colous on the way that colours were digitally modified trough whole tone range by increasing (darker) or decreasing (lighter) particular colour for $2 \%$ of middle tone values of the CMYK colours on tested images as shown in the table:

\section{Table 1. Sample identification}

\begin{tabular}{|l|l|}
\hline $\begin{array}{l}\text { \% of increased (decreased) } \\
\text { middle tone value }\end{array}$ & $\begin{array}{l}\text { Sample } \\
\text { initials }\end{array}$ \\
\hline $2 \%$ Cyan & $2 \% \mathrm{C}$ \\
\hline $4 \%$ Cyan & $4 \% \mathrm{C}$ \\
\hline $6 \%$ Cyan & $6 \% \mathrm{C}$ \\
\hline $2 \%$ Magenta & $2 \% \mathrm{M}$ \\
\hline $4 \%$ Magenta & $4 \% \mathrm{M}$ \\
\hline $6 \%$ Magenta & $6 \% \mathrm{M}$ \\
\hline $2 \%$ Yellow & $2 \% \mathrm{Y}$ \\
\hline $4 \%$ Yellow & $4 \% \mathrm{Y}$ \\
\hline $6 \%$ Yellow & $6 \% \mathrm{Y}$ \\
\hline $2 \%$ Darker & $2 \% \mathrm{D}$ \\
\hline $4 \%$ Darker & $4 \% \mathrm{D}$ \\
\hline $6 \%$ Darker & $6 \% \mathrm{D}$ \\
\hline$-2 \%$ Lighter & $8 \% \mathrm{~L}$ \\
\hline$-4 \%$ Lighter & $6 \% \mathrm{~L}$ \\
\hline$-6 \%$ Lighter & $4 \% \mathrm{~L}$ \\
\hline & \\
\hline
\end{tabular}

Testing prints were made together with grey balance field and all colour modifications in prints affected colour change in grey balance field. Testing prints and grey balance field are shown with figure A.1.

For visual testing, observers were asked to choose 5 best matching prints with the original photos focusing on the forehead of the face. With binocular simultaneous matching method, 60 observers have chosen the best matching prints under specified light conditions.

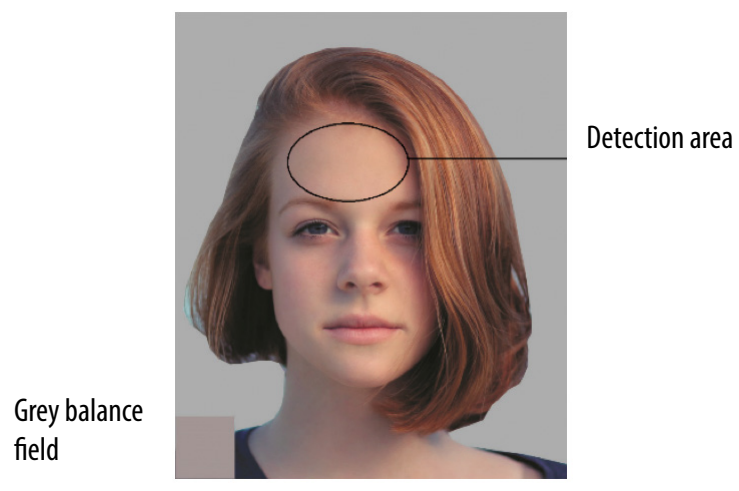

Figure 3. Original photo, grey balance field, skin detection area

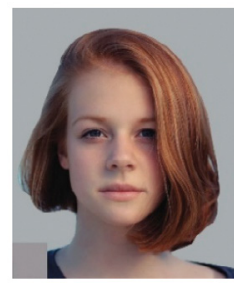

a) $2 \% \mathrm{C}$

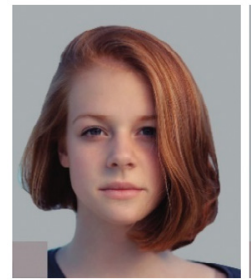

d) $2 \% \mathrm{M}$

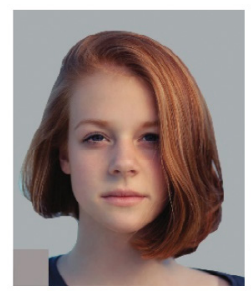

g) $2 \% \mathrm{Y}$

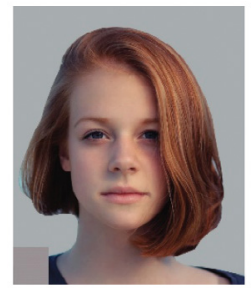

j) $2 \% \mathrm{D}$

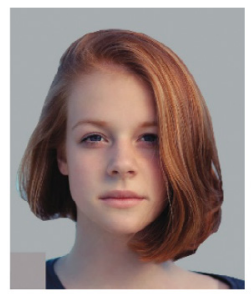

m) $-2 \% L$

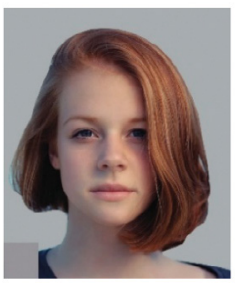

b) $4 \% \mathrm{C}$

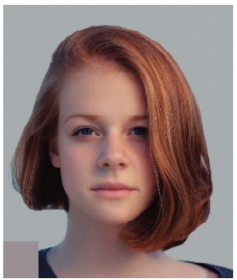

e) $4 \% \mathrm{M}$

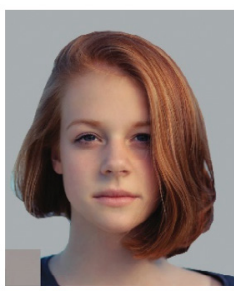

h) $4 \% \mathrm{Y}$

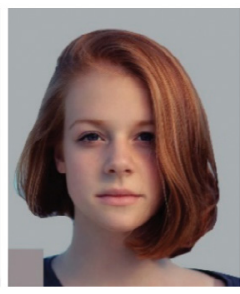

k) $4 \% \mathrm{D}$

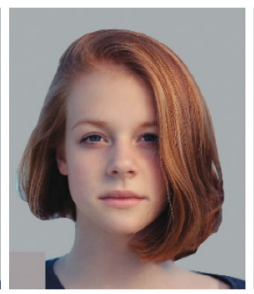

n) $-4 \% \mathrm{~L}$

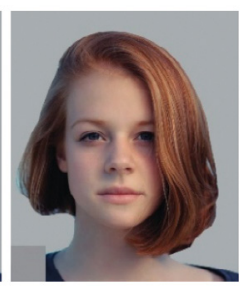

c) $6 \% \mathrm{C}$

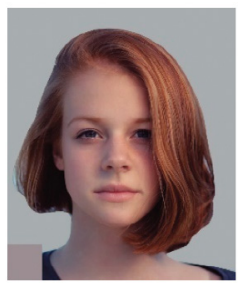

f) $6 \% \mathrm{M}$

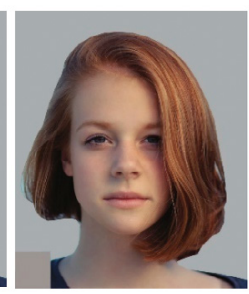

i) $6 \% \mathrm{Y}$

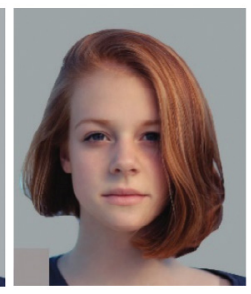

I) $6 \% \mathrm{D}$

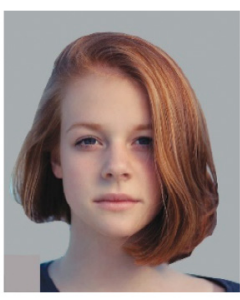

o) $-6 \% \mathrm{~L}$
Figure 4. Testing prints 
These matching prints were ranked as described: the first with 5 points, the second with 4 points, the third with 3 points, the fourth with 2 points, and the last matching 1 point.

The research was done on the Faculty of Graphic arts, under standardized condition box (GTI) - Graphic Technology. Inc. / CRD -1 , testing from view angle (Figure 4.), and in standardized viewing box for LED light.

To all samples that were chosen as the best, observers added 5 points, second matching was added 4 points, third matching 3 points, fourth matching 2 points, and last matching with 1 point. So, for every light source, five best matching samples were shown in following figures:

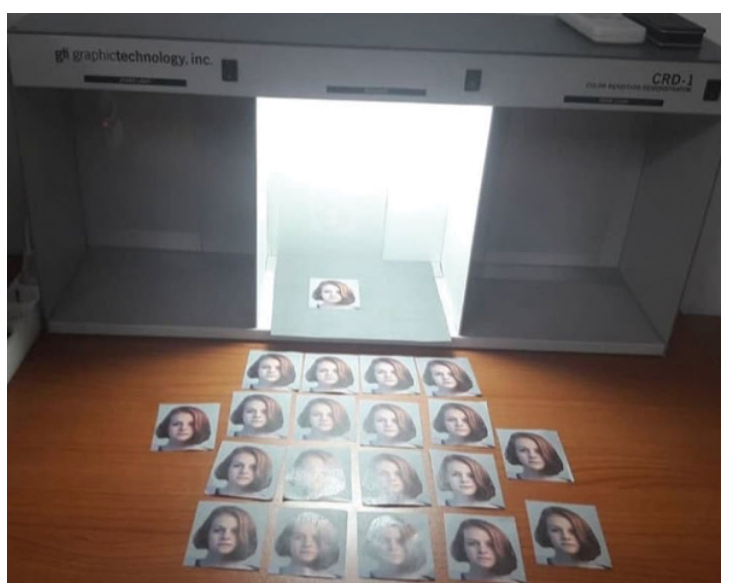

Figure 5. Standard box

So, all best matching samples are shown on Table A.2.

\section{Table 2. Best matching samples on different} SPDs

\begin{tabular}{|l|}
\hline Sample initials / SPD \\
\hline 1) $4 \% \mathrm{Y} /$ Store Light \\
\hline 2) $2 \% \mathrm{Y} /$ Day Light \\
\hline 3) $2 \% \mathrm{M} /$ Home Light \\
\hline 4) $2 \% \mathrm{C} /$ Led Light $6500 \mathrm{~K}$ \\
\hline 5) $2 \% \mathrm{M} /$ Led Light $2700 \mathrm{~K}$ \\
\hline 6) $2 \% \mathrm{D} /$ Led Light $4000 \mathrm{~K}$ \\
\hline
\end{tabular}

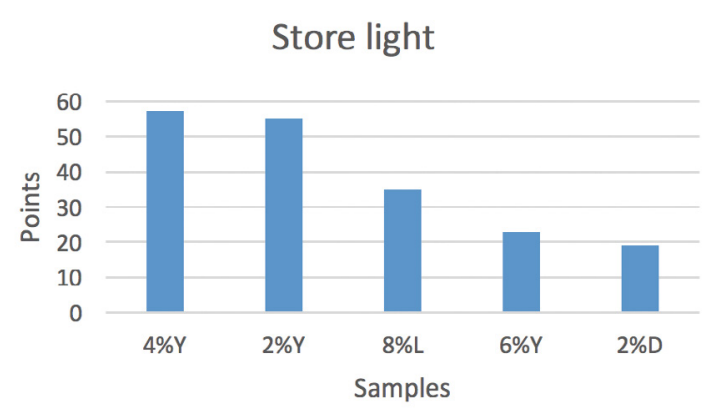

Figure 6. Observers matching results under Store light.

Day light sources

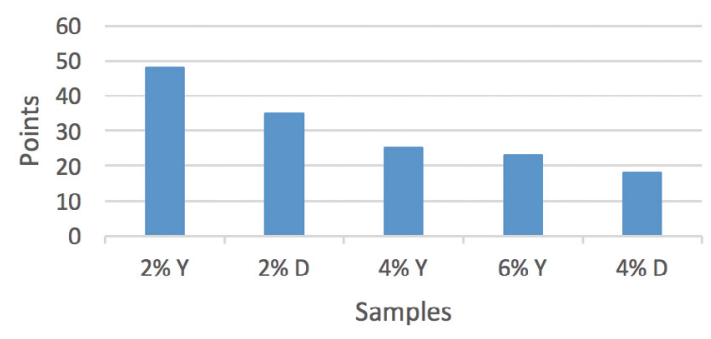

Figure 7. Observers matching results under Day light sources.

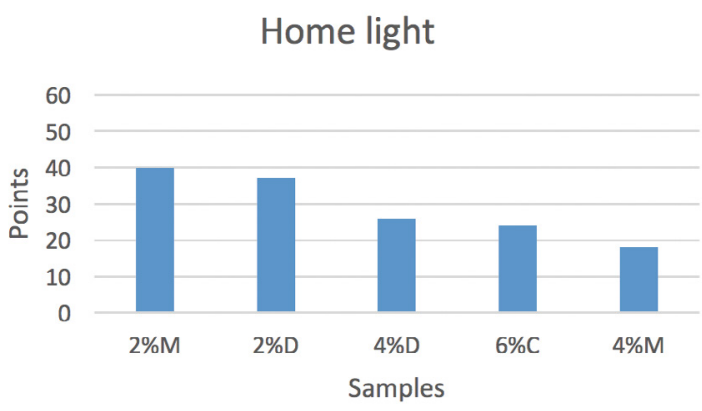

Figure 8. Observers matching results under Home light.

Led light $6500 \mathrm{k}$

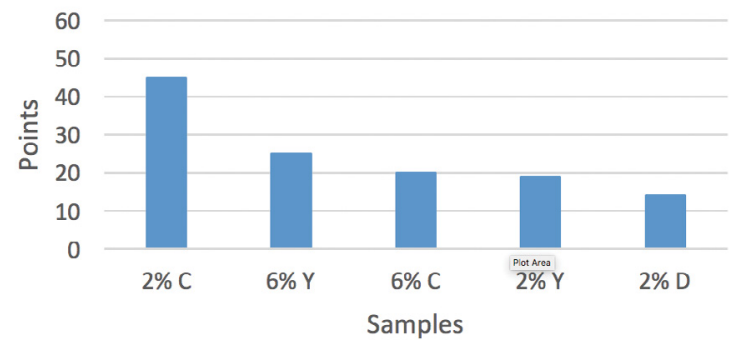

Figure 9. Observers matching results under Led light $6500 \mathrm{~K}$ 
Led light $2700 \mathrm{k}$

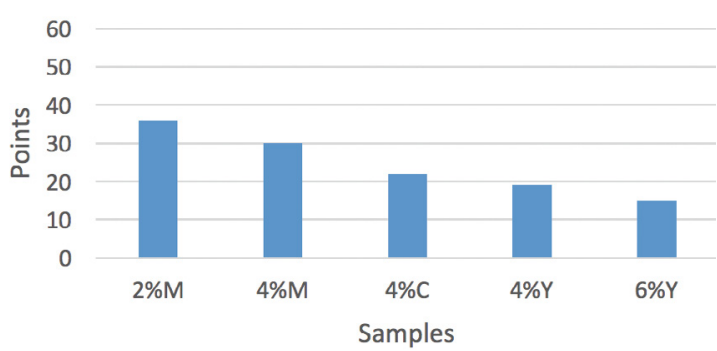

Figure 10. Observers matching results under Led light $2700 \mathrm{~K}$

Led light $4000 \mathrm{k}$

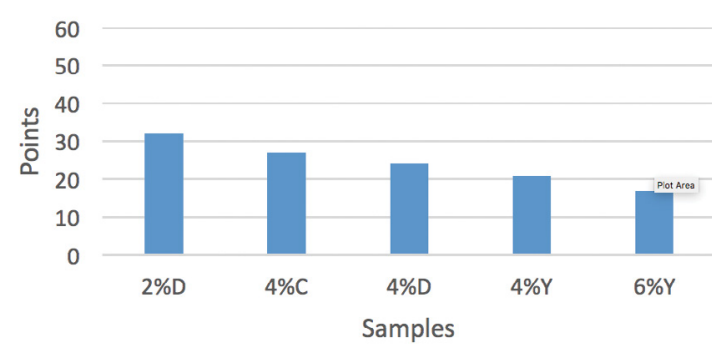

Figure 11. Observers matching results under Led Light $4000 \mathrm{~K}$

\subsection{GREY BALANCE TESTING}

After the research of visual perception was done, we measured CIE $L^{\star} a^{\star} b^{\star}$ colorimetric values of grey balance field of best matching print samples to find Metameric Index (MI).

All measurements were done with Spectro Eye X-RITE under standardized measurement conditions (ISO 13655:2017), and an average of $10 \mathrm{CIE} \mathrm{L}^{\star} \mathrm{a}^{\star} b^{\star}$ measures were calculated as follows:

$$
\text { average }=\frac{1}{b-a} \int_{-a}^{b} f(x) d x
$$

where standard deviation was calculated:

$$
S=\sqrt{\frac{\sum_{i=1}^{N}\left(x_{i}-\bar{x}\right)^{2}}{N-1}}
$$

Metamerism index MI was calculated according to relation (1).

The measuring results of best matching samples under specified light sources were shown on Table 3.

These results are shown on 3D graph as well to see how colorimetric values are changed depending on light source in CIE $\mathrm{L}^{\star} \mathrm{a}^{\star} \mathrm{b}^{*}$ colour space.

\begin{tabular}{|c|c|c|c|c|c|c|c|c|c|c|c|}
\hline \multirow{2}{*}{ Samples } & \multicolumn{3}{|c|}{ Original } & \multicolumn{3}{|c|}{ Samples } & \multirow{2}{*}{$\Delta \mathbf{L}$} & \multirow{2}{*}{$\Delta \mathrm{C}$} & \multirow{2}{*}{$\Delta \mathbf{H}$} & \multirow{2}{*}{ MI } & \multirow{2}{*}{$\Delta \mathrm{ab}$} \\
\hline & $\mathbf{L}^{*}$ & $\mathbf{a}^{*}$ & $\mathbf{b}^{*}$ & $\mathbf{L}^{*}$ & $\mathbf{a}^{*}$ & $\mathbf{b}^{*}$ & & & & & \\
\hline $4 \%$ Y / Store Light & 58.01 & 1.65 & -4.87 & 59.41 & -0.55 & -3.13 & 1.4 & 2.23 & 2.97 & 3.64 & 2.8 \\
\hline $2 \%$ Y / Day Light & 58.01 & 1.65 & -4.87 & 59.52 & 0.39 & -3.54 & 1.53 & 1.87 & 1.35 & 2.45 & 1.83 \\
\hline $2 \% \mathrm{M} /$ Home Light & 58.01 & 1.65 & -4.87 & 60.46 & 1.96 & -5.66 & 2.45 & 0.91 & 0.05 & 2.29 & 0.84 \\
\hline $\begin{array}{l}2 \% \text { C / Led Light } \\
6500 \mathrm{~K}\end{array}$ & 58.01 & 1.65 & -4.87 & 59.32 & -0.3 & -2.1 & 1.3 & 3.31 & 2.28 & 3.78 & 3.39 \\
\hline $\begin{array}{l}2 \% \mathrm{M} / \text { Led Light } \\
2700 \mathrm{~K}\end{array}$ & 58.01 & 1.65 & -4.87 & 60.46 & 1.96 & -5.66 & 2.45 & 0.91 & 0.05 & 2.29 & 0.84 \\
\hline $\begin{array}{l}2 \% \mathrm{D} / \text { Led Light } \\
4000 \mathrm{~K}\end{array}$ & 58.01 & 1.65 & -4.87 & 59.1 & 0.63 & -4.54 & 1.09 & 0.82 & 1.32 & 1.75 & 1.07 \\
\hline
\end{tabular}

Table 3. $L^{*} a^{*} b^{*}$ values on best matching print samples 


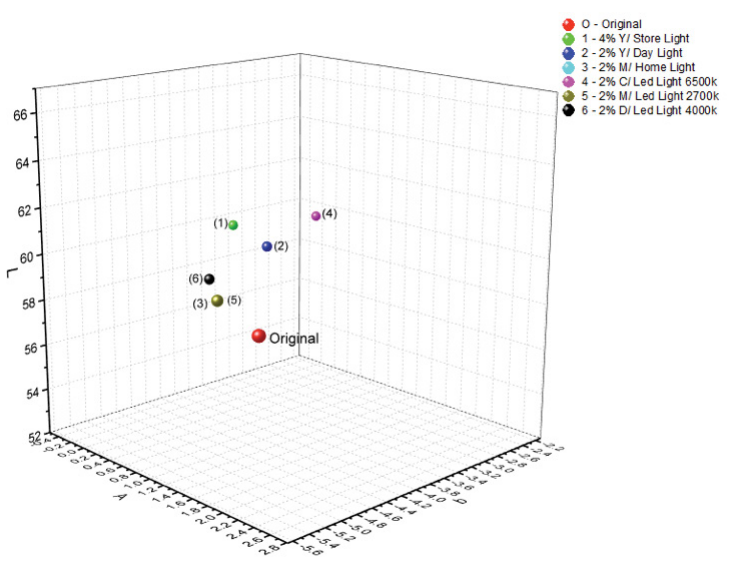

Figure 12. Print $L^{*} a^{*} b^{*}$ values of measuring samples.

\section{Conclusion}

The obtained results in this research paper denotes that by illuminant metamerism measurements, there can occur the deviation of colors in tiny values. Illuminant metamerism depends on different SPD-s that can have an effect directly on visual perception and on graphic industry, since the color deviations always occur on printing, on illuminant metamerism and observer. According to these results the color areas for printing have been developed, to a tiny percentage of difference in color, in which metamerism is occurred depending on the difference of illuminant. As a conclusion according to $L^{*} a^{*} b^{*}$ values, the original photography finds the resemblance mostly with the best comparative sample under the LED $4000 \mathrm{~K}$ light, it is supposed to be the most resembling, observed in $2 \%$ of the increased middle tone values of the CMYK colours on tested images where MI is lower in value of 1.75 .

Hereby it can be concluded that the LED $4000 \mathrm{~K}$ light can be the most approximate to the best perception of the given examples, by the smallest metamerism, aiming to contribute to the graphic industry, avoiding the metamerism discrepancy.

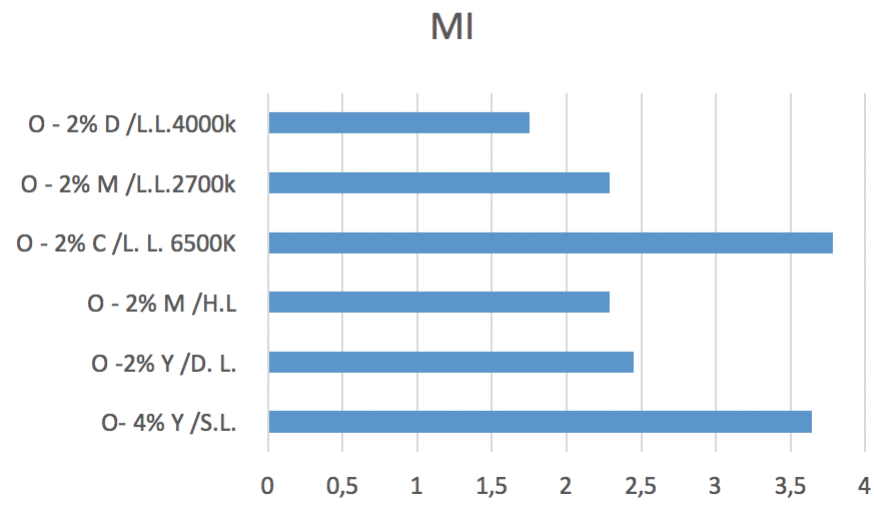

Figure 13. MI values regarding different light sources
During the indoor illuminant enlightenment and the presence of LED $2700 \mathrm{~K}$, the observer picks out the best matched of 2\% $\mathrm{M}$ of increased middle tone values of the CMYK colours on tested images. The maximum deviation of the color samples referred to illuminant metamerism under the LED $6500 \mathrm{~K}$ light, it is predicted the photography that is matched on $2 \%$ of the increased middle tone values of the CMYK colours on tested images MI was 3.78.

As LED light is an increasingly used light source due to very low energy consumption, it is to be assumed that in the future almost all artificial lighting will be with this light. Therefore, printers engaged in the production of graphic products will switch to LED lighting and the metamerism that appears will be a challenge to solve problems in the reproduction of graphic products. This research creates preconditions for further research in this area, especially with the problem of using light in non-standard conditions, which are very common in real graphic production. By solving the assumptions of the appearance of metamerism with LED light, possible complaints of customers will be avoided, and the quality of the graphic product will be greatly increased. 


\section{References}

1. Fairchild D. Mark, Rosen R. Mitchell, Johnson M. Garrett, Spectral and Metameric Color Imaging, Published 2001,

2. Zarit D. Benjamin, Super J. Boaz, Quek K. H. Francis, Comparison of Five Color Models in Skin Pixel Classification, Published in Proceedings International Workshop on Recognition Analysis, and Tracking of Faces and Gestures in Real-Time Systems. In Conjunction with ICCV'99 (Cat. No.PR00378)1999 DOI:10.1109/RATFG.1999.799224

3. Wyszecki G. and Stiles S.W., Color Science, 2nd Ed., Wiley, New York, 1982, page 224

4. T.M. Goodman, 2012 'International standards for colour', Colour Design (Second Edition) Theories and Applications Woodhead Publishing Series in Textiles 2012, Pages 417-452, https://doi. org/10.1016/B978-0-08-101270-3.00018-7

5. 4. Stevens R. Wallace (1951). Principles of Lighting. Constable Original from the University of Wisconsin - Madison, Digitized Nov 28, 2007
6. Berns S. Roy, Billmeyer and Saltzman's “Principles of Color Technology" 4th Edition, This edition first published 2019 @ 2019 year John Wiley \& Sons Inc. ISBN 9781119367192 (Adobe PDF) pp. 149

7. Chi N., Fudan University, Shanghai, China/LED -Based Visible Light Communications ISSN 18604862 ISSN 1860-4870 (electronic)

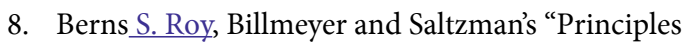
of Color Technology" 4th Edition, This edition first published 2019 @ 2019 year John Wiley \& Sons Inc. | ISBN 9781119367192 (Adobe PDF) pp.157yszecki G. and Stiles S.W., Color Science, 2nd Ed., Wiley, New York, 1982

9. Berns S. Roy, The proper use of indices of metamerism, Color Research \& Application 33(6):509 - 512 - December 2008, DOI: 10.1002/ col.20450

10. Konig F. and Herzog P., "On the Limitations of Metameric Imaging”, Proceedings of IS\&T PICS, 1999, pp. 163-168.

11. Lee Ch. Hsien, Introduction to color imaging 2005, Cambridge University Press, pp.141-142 
